\title{
Temporal Sampling: How Many Sections Are Needed to Quantify the Mean Transport and Structure of a Meandering Current?
}

\author{
Christopher S. Meinen \\ Cooperative Institute for Marine and Atmospheric Studies, University of Miami, Miami, Florida
}

(Manuscript received 6 February 2004, in final form 23 August 2004)

\begin{abstract}
Two years of observations from an array of 16 inverted echo sounders deployed south of Australia near $51^{\circ} \mathrm{S}, 143.5^{\circ} \mathrm{E}$ are combined with hydrographic observations from the region to estimate the differences in baroclinic transport, as well as temperature and velocity structure, that result from trying to estimate the true mean using a limited number of snapshot sections. The results of a Monte Carlo-type simulation suggest that over a 350-km distance, completely spanning the Subantarctic Front (SAF) at most times, a minimum of six temporally independent sections would be required to determine the baroclinic transport mean (surface to $4000 \mathrm{db}$ ) of the observed 2-yr period to within an accuracy of $10 \%$ when the sections are averaged in either an Eulerian (geographic) or stream coordinates manner. However, even with 10 sections during a 2-yr period the details of the mean velocity and temperature structures obtained can be quite different than the "true" 2-yr mean structure, regardless of whether the sections are averaged in either Eulerian or stream coordinates. It is estimated that at least 20 independent sections would be required during a 2-yr period in order to determine the baroclinic velocity structure to within an accuracy of $10 \%$, irrespective of whether they are averaged in Eulerian or stream coordinates. Implications for future sampling strategies and for inverse modeling analyses are discussed.
\end{abstract}

\section{Introduction}

Hydrographic sampling of the ocean, whether by expendable bathythermograph casts on volunteer observing ships or by conductivity-temperature-depth (CTD) casts on research vessels, has been one of the most powerful and most commonly used techniques in the study of oceanic currents over the past few decades (nearly a century, in fact). Scores, perhaps hundreds, of scientific articles have been written describing ocean fronts and the associated currents solely on the basis of hydrographic section data. In addition to providing snapshot descriptive reports of current structure and water mass properties, hydrographic section data have been combined with advanced techniques, such as inverse modeling (Wunsch 1996), to provide estimates of both the mean circulation and dynamically important quantities, such as diapycnal mixing, in various parts of the oceans (e.g., Lumpkin and Speer 2003). Repeated hydrographic sections have also been used to estimate temporally varying circulation patterns (e.g., Koltermann et al. 1999).

While studies such as these have provided critically

Corresponding author address: Dr. Christopher S. Meinen, NOAA/AOML/PHOD, 4301 Rickenbacker Causeway, Miami, FL 33149.

E-mail: Christopher.Meinen@noaa.gov important and useful information about oceanic currents such as the Gulf Stream and the Antarctic Circumpolar Current (ACC), a nagging well-known problem has been that all of these hydrographic sections provide only snapshot estimates of the observed properties and are influenced by all time scales from hourly to multidecadal. Moored observations by current meters and other instruments have demonstrated the wide range of periods at which energetic oceanic variability exists (e.g., Shay et al. 1995; Phillips and Rintoul 2000), and therefore hydrographic section data must always be interpreted with the careful consideration of the "aliasing" caused by signals at periods other than those that are of interest. Ideally, moored observations can provide more than just a cautionary warning regarding the interpretation of snapshot hydrographic data. Since moored instruments provide observations of signals at nearly all time scales (limited by the record length and sampling rate, of course), these moored instrument records can also provide an estimate of the temporal variance and therefore can be used to calculate how many snapshot sections would be required to describe something that closely represents the "true" mean transport and structure of a current/front during the period when the moorings were in place.

The Sub-Antarctic Flux and Dynamics Experiment (SAFDE) consisted of a large number of moored instruments (current meters, inverted echo sounders, and 
horizontal electric field recorders) that were deployed near $51^{\circ} \mathrm{S}, 143.5^{\circ} \mathrm{E}$ for a 2 -yr period from March 1995 until April 1997 (Luther et al. 1997). The array location was designed to span the location of the Subantarctic Front (SAF), the stronger of the two main branches/ fronts of the ACC. The other strong branch of the ACC, the Polar Front (PF), does not enter the SAFDE region during most of the study period (K. Tracey 2003, personal communication). The moored data collected during SAFDE, along with hydrographic data collected during and prior to the experiment, have been used to provide the most complete descriptions of the structure of the SAF current and the transport along and across the front to date (Watts et al. 2001; Meinen et al. 2002; Sun and Watts 2002; Meinen and Luther 2003; Meinen et al. 2003; Chave et al. 2004). While the structure and transport of the SAF at this location have now been fairly well determined, albeit for this 2-yr period only, the time series of observations provide the opportunity for improving the design of further studies of the SAF at this and other locations along its path, and more generally for the designing of studies of strong ocean currents globally.

The purpose of this paper is to determine the minimum number of snapshot sections that would be needed to accurately estimate the mean transport along the SAF within the limited range $(350 \mathrm{~km})$ of the SAFDE study area. Mean transports and velocity structures are calculated first in Eulerian (geographic) coordinates. The small spatial extent of the SAFDE array $(350 \mathrm{~km})$ limits the applicability of the Eulerian results as compared to basin-crossing hydrographic sections, so the transports and velocities are also calculated in "stream coordinates" and the results are contrasted with the Eulerian results. Stream coordinates refers to a coordinate system fixed to some unique characteristic of a moving current rather than to a point on the earth, and they represent a commonly used technique for averaging observations of a meandering current so that the meandering effects can be removed from the observations prior to averaging (e.g., Halkin and Rossby, 1985; Meinen and Luther, 2003). Surprisingly, it will be shown that the number of sections that would be required to accurately describe the mean temperature and baroclinic velocity structure of the SAF may be prohibitively expensive regardless of whether Eulerian or stream coordinate averaging is applied due to the high observed variability. The mean baroclinic transport, however, will be shown to be quantifiable with a reasonable number of sections. The paper is organized as follows. First, the data used will be described along with a brief explanation of the sampling and averaging methods used herein. Next there will be a presentation of the results of the Eulerian averaging simulations, followed by a discussion of the stream coordinates averaging results. Finally, a brief conclusion section will comment on the implications of these results on future experiments.

\section{Data and methods}

The SAFDE experiment involved a large array of current meter moorings (CMMs), inverted echo sounders (IESs), and horizontal electric field recorders (HEFRs); the CMMs were deployed in a small cluster within the larger IES and HEFR array (Fig. 1).

Good data were returned from 17 IESs, 12 HEFRs, and 17 current meters on seven moorings. CTD profiles were obtained within the SAFDE region on two SAFDE cruises and on six World Ocean Circulation Experiment (WOCE) SR3 cruises (Rintoul and Sokolov 2001); two of the WOCE cruises also occurred during the SAFDE period. The calculations presented herein are based on the 16 IES moorings within the main array plus one pseudo-IES that fills a spatial gap in the eastern line. The latter was created using three temperature-pressure sensor pairs (from 300 to 1000 $\mathrm{m})$ on the easternmost mooring following the methods presented in Meinen and Watts (2000).

An IES is about $0.6 \mathrm{~m}$ tall and is moored roughly $1 \mathrm{~m}$ off the ocean bottom. The IESs used in SAFDE transmit a $10-\mathrm{kHz}$ sound pulse and measure the time $(\tau)$ for the pulse to travel to the ocean surface and back (Watts and Rossby 1977; Chaplin and Watts 1984). Using either hydrography gathered during the IES deployment period or historical hydrography, both from the region of study, characteristic relationships between $\tau$ and other oceanic variables (e.g., temperature $T$, salinity $S$, specific volume anomaly $\delta$ ) can be developed and combined with the IES-measured $\tau$ to estimate full water column profiles of these variables (Meinen and Watts 2000; Watts et al. 2001). These empirical relationships are referred to as the gravest empirical modes (GEMs); and there are separate GEM representations for $T, S$, and $\delta$. The success of the method in a particular region indicates that subinertial property variations at different depth levels are highly correlated with one another, although this does not imply that the vertical structure follows a particular analytical mode structure [see Watts et al. (2001) for more discussion]. Vertically integrating the $\delta$ profiles provides profiles of geopotential height anomaly $(\Delta \Phi)$ that when differenced horizontally between neighboring IES sites yield profiles of the relative velocity using the geostrophic (dynamic) method. Two-dimensional arrays of IESs provide both components (north and east) of the baroclinic velocity relative to an arbitrary level of no motion ( $4000 \mathrm{db}$ is used throughout this paper for the level of no motion for the geostrophic relative velocities).

The GEM fields used herein were derived following the methods presented in Meinen and Watts (2000). The IES-measured $\tau$ values were mapped onto a $10-\mathrm{km}$ grid using optimal interpolation (OI) via the standard methods (Bretherton et al. 1976). The details of how the OI-mapped $\tau$ values were combined with the GEM fields to yield vertical profiles of temperature and relative velocity are presented in Meinen et al. (2002) and 

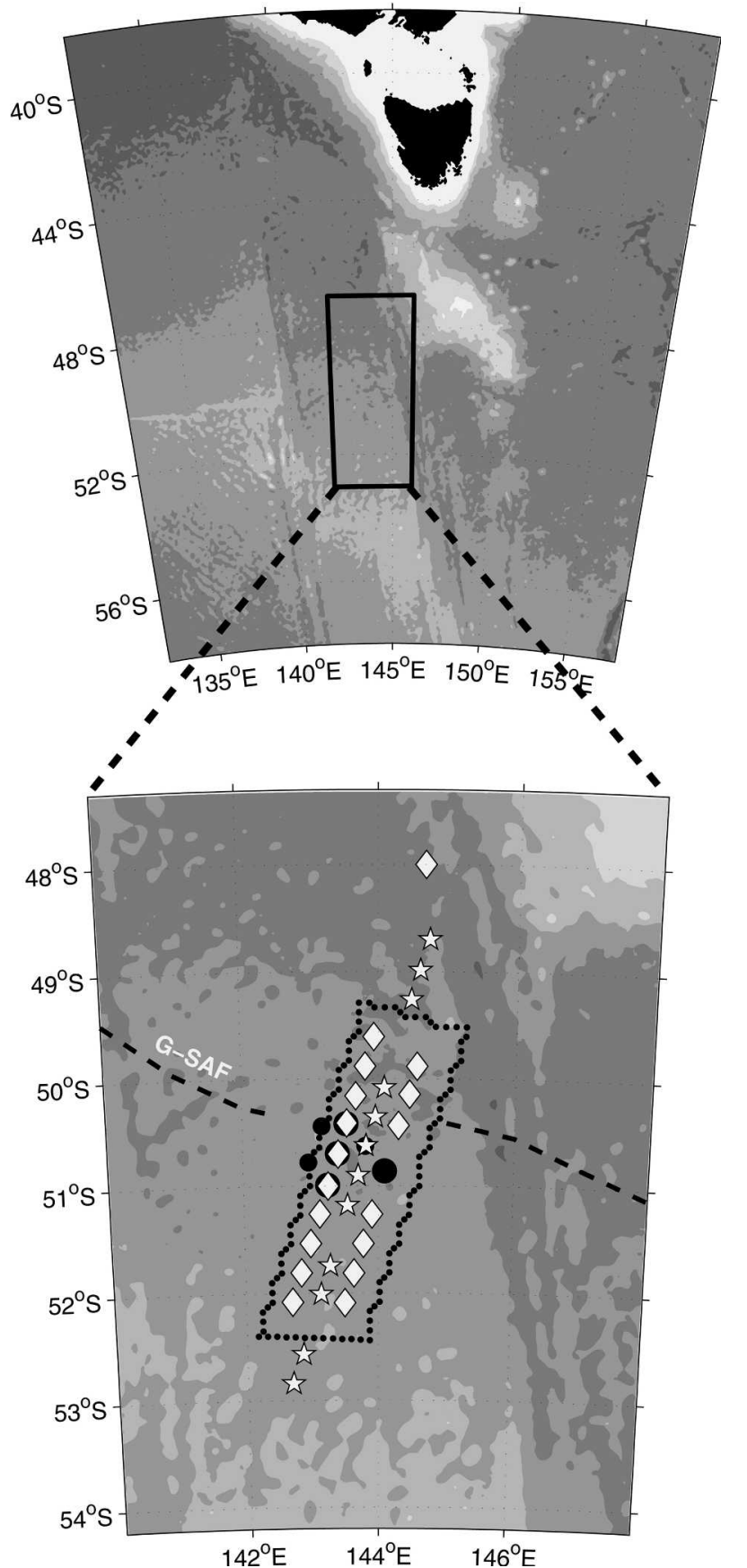

FIG. 1. Location of the SAFDE array. White diamonds, white stars, large black circles, and small black circles indicate IES, HEFR, tall CMM, and short CMM locations, respectively. The dotted line indicates OI mapping domain. Bottom topography from Smith and Sandwell (1997) is denoted by shading at a contour interval of $1000 \mathrm{~m}$; most of the SAFDE array region is 3000 $4000 \mathrm{~m}$ deep. Black areas indicate land. The mean SAF position determined by Gille (1994) from Geosat sea surface height gradients for 1986-89 is shown as a thick dashed line (labeled G-SAF). will not be repeated here for the sake of brevity. Suffice it to say that once combined in this manner the result is a four-dimensional grid $(x, y, z$, and time) of temperature $^{1}$ and relative velocity over the OI mapping region illustrated in Fig. 1 (the accuracy of these estimates will be discussed shortly). As an aside, one advantage of these velocities is that they represent geostrophic integrations between the IES sites, rather than point measurements such as those made by current meters; spatial sampling is another well-known oceanographic problem, of course, but it is beyond the scope of the current paper to get into the distinction between geostrophically integrated transports and point measurements. Temporal resolution of the data used herein is daily, with all time series having been smoothed with a 5-day running mean; a mean annual cycle (very weak) has been removed from the IES data prior to OI mapping to focus on the mesoscale signals.

To simulate the observations of a hydrographic section using this $4 \mathrm{D}$ dataset, a vertical "cut" through the data must be chosen. The western line of IESs was along the WOCE SR3 repeat hydrography line, and initially this seemed like the logical choice to use as the Eulerian example for this study. The mooring results, however, indicate that the SR3 line crosses the SAF at a highly oblique angle during the 2-yr experiment (Meinen et al. 2002, 2003). This would have little effect on transport calculations but would result in a mean vertical structure picture that was grossly oversmoothed and overbroad, complicating the analysis of structure central to this study. Using a section orthogonal to the mean path of the SAF would be optimal; however, the mean path direction was $60^{\circ} \mathrm{T}$ (Meinen et al. 2003) and given the shape of the SAFDE array this would yield a very short simulated section. The best compromise of a near-orthogonal crossing of the SAF versus sufficiently long section was to use a north-south section (Fig. 2).

This section also has the advantage that cross-section flows are zonal, and along-section flows, which would normally be invisible to geostrophic section calculations, are meridional.

For each day, temperature and relative velocity profiles were extracted at $10-\mathrm{km}$ resolution along $143.8^{\circ} \mathrm{E}$ (solid line in Fig. 2). The "true" mean sections of temperature $T$, zonal velocity $u$, and meridional velocity $v$ were defined as the average of the 701 daily sections of these quantities. Transport was defined as the integral of the zonal velocity (which is relative to an assumed level of no motion at $4000 \mathrm{db}$ ) from the surface to 4000 $\mathrm{db}$ and from one end of the mapping region to the other, a distance of $350 \mathrm{~km}$.

To simulate the sampling of a series of CTD sections

\footnotetext{
${ }^{1}$ Salinity has also been determined for the same region, but it will not be presented herein, as the results are similar to those for temperature.
} 


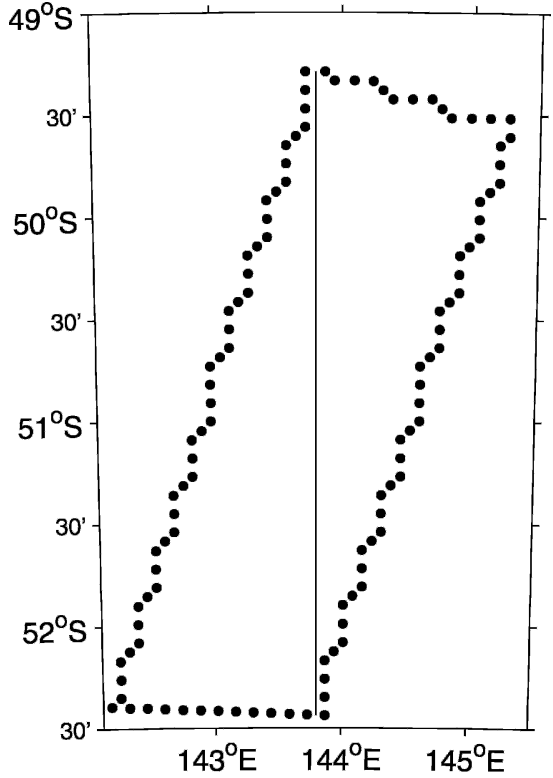

FIG. 2. Section chosen for simulating repeated hydrographic sections (vertical line). The dotted line indicates OI mapping domain.

obtained during the 2-yr experiment, random days were chosen to represent individual snapshot sections. ${ }^{2}$ Choosing truly random days could result in consecutive days, or days very close to one another, being chosen. Because this would be a poor simulation of real hydrographic section sampling, in which sections are obtained months or years apart in time, the random days chosen were forced to be at least one integral time scale (Emery and Thomson 1997) apart from one another; the integral time scale of the IES data, 12 days, was used for this calculation. ${ }^{3}$ The resulting set of sections can therefore be considered "independent" observations of the current structure and transport.

A further concern is that any one random subset of days could provide an estimate of the mean that was particularly inaccurate while another subset could provide an average very similar to the true mean. To address this issue a Monte Carlo-type of approach was adopted wherein 100-5000 ensembles of each random sampling were calculated, and statistics were developed for quantifying the "error" between the sample mean and the true mean based on these repeated samplings. For example, the error between an average of 10 snapshot sections and the true mean was quantified as fol-

\footnotetext{
${ }^{2}$ Note that the asynopticity of a real CTD section could add additional error that will not be simulated by choosing synoptic snapshots in this manner.

${ }^{3}$ This calculation will vary for oceanic currents with different integral time scales; for example, Johns et al. (1995) found that the Gulf Stream near $68^{\circ} \mathrm{W}$ had an integral time scale of about 7.5 days.
}

lows. Ten "independent" days were randomly selected and the transports on these 10 days were averaged together to provide an estimate for the mean transport across the section. The difference between this mean value and the true mean was defined as a single example of the error in determining the mean using only 10 sections. This process was repeated as many as 5000 times, each time selecting a new random set of 10 independent days and determining the transport error between the section-average transport and the true mean. The final error for using 10 sections to determine the mean was then calculated as the root-mean-square (rms) value of the up to 5000 individual error values from the random samplings.

The stream coordinates averaging proceeded essentially the same way as described above for the Eulerian averaging, with a few important differences in how the snapshots of data were extracted from the 4D fields. Focusing still on the $143.8^{\circ} \mathrm{E}$ line, the location at which the core ${ }^{4}$ of the SAF crossed $143.8^{\circ} \mathrm{E}$ was found, and the direction of the flow was determined as the tangent to the SAF core ${ }^{5}$ through the array at the point of intersection with $143.8^{\circ} \mathrm{E}$. Only days with a single crossing were used (days with tight S-shaped meanders are excluded, as were days when the core did not cross $143.8^{\circ} \mathrm{E}$ within the OI mapping area). A line orthogonal to the downstream direction was determined, and velocity and temperature was extracted along that line. Figure 3 illustrates the geometry of the stream coordinates section for one example day.

Because the direction of downstream and the location of the core varies from day to day, the length of "section" available on any given day varies; some days the section reaches $\pm 200 \mathrm{~km}$ from the core (only 2 days), while on most days the section extends at most $\pm 80 \mathrm{~km}$ or less on either side of the core. Days for extracting the stream coordinates sections are chosen in a random manner as described above, although fewer days are available for selecting, as some days had either multiple core crossings along $143.8^{\circ} \mathrm{E}$ or had none. Once the stream coordinates sections were extracted from the 4D arrays of temperature and velocity estimates, they were averaged together in the same manner as above except for having an abscissa of cross-stream distance rather than latitude.

Finally, a brief mention must be made regarding the impact of errors in the IES-estimated temperatures and relative velocities. Watts et al. (2001) compared the relative velocities from the SAFDE IESs to coincident direct velocity measurements from current meters (see Fig. 1) and determined that the daily relative velocity estimates from the IESs are accurate to within \pm 7

\footnotetext{
${ }^{4}$ The core is defined as the location where the $6^{\circ} \mathrm{C}$ isotherm crosses $500 \mathrm{db}$, based on the results in Meinen and Luther (2003).

${ }^{5}$ Defined as the path of the core contour in the OI-mapped fields.
} 


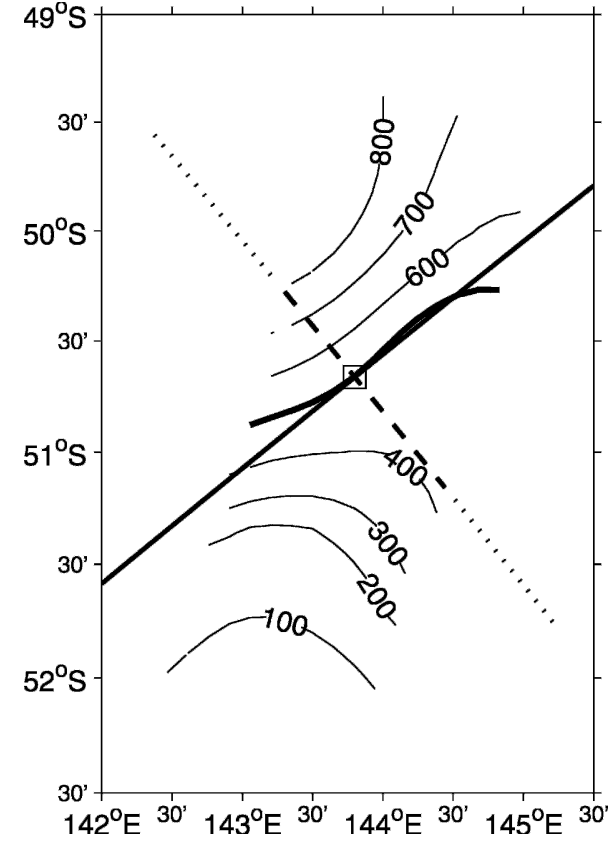

FIG. 3. Schematic illustrating how the stream coordinates data were extracted from the 4D grids of temperature and velocity estimates. The contoured field is the $6^{\circ} \mathrm{C}$ isotherm depth $(\mathrm{db})$ for $26 \mathrm{Feb} 1997$; the $6^{\circ} \mathrm{C}$ isotherm is roughly the middle of the main thermocline in this region. The bold contour is the $500-\mathrm{db}$ contour, defined as the core of the SAF (after Meinen and Luther 2003). The bold straight line illustrates the direction of downstream flow on this particular day, while the bold dashed line indicates the line along which the stream coordinates section would be extracted on this day. The dotted lines illustrate the fact that the length of the stream coordinates section available on any given day varies depending upon how much of the line is within the OI mapping domain of the array of IESs. $\mathrm{cm} \mathrm{s}^{-1}$ at $300 \mathrm{~m}$ and to within $\pm 3 \mathrm{~cm} \mathrm{~s}^{-1}$ at $1000 \mathrm{~m}$. The temperature accuracy for daily estimates ranges within $0.05^{\circ}-0.40^{\circ} \mathrm{C}$ below the upper $100-200 \mathrm{db}$ (Meinen et al. 2003). The real test, however, is how well subsamples of daily sections can reproduce the true mean of those sections given the observed variability; inaccuracies in the individual "true" IES-derived sections relative to the real ocean are irrelevant in this context.

\section{Results}

The 2-yr period of the SAFDE encompassed a wide range of variations in the path and structure of the SAF (e.g., Meinen et al. 2003). To illustrate this variability, Fig. 4 presents three daily maps of the depth of the $6^{\circ} \mathrm{C}$ isotherm $\left(Z_{6}\right)$ as estimated using the OI-mapped $\tau$ data and the $T$ GEM field.

The bold contours in these maps represented the line along which $Z_{6}$ crosses $500 \mathrm{db}$, which has been shown to be the nominal location of the center of the baroclinic front at this location (Meinen and Luther 2003). As is clear from these 3 days, the SAFDE domain saw rings (4 October 1996), meanders (3 August 1996), and possibly splitting of the current (9 April 1995) over the course of the study. None of this will surprise any veteran analyst of mooring data in strong ocean currents; these same types of features are observed in the Gulf Stream and in other major currents worldwide. Those planning and analyzing hydrographic data are aware of this variability as well, of course, and they make an effort to account for it as best as they can. The data from the SAFDE experiment provide an opportunity to quantify just how large the errors in transport and
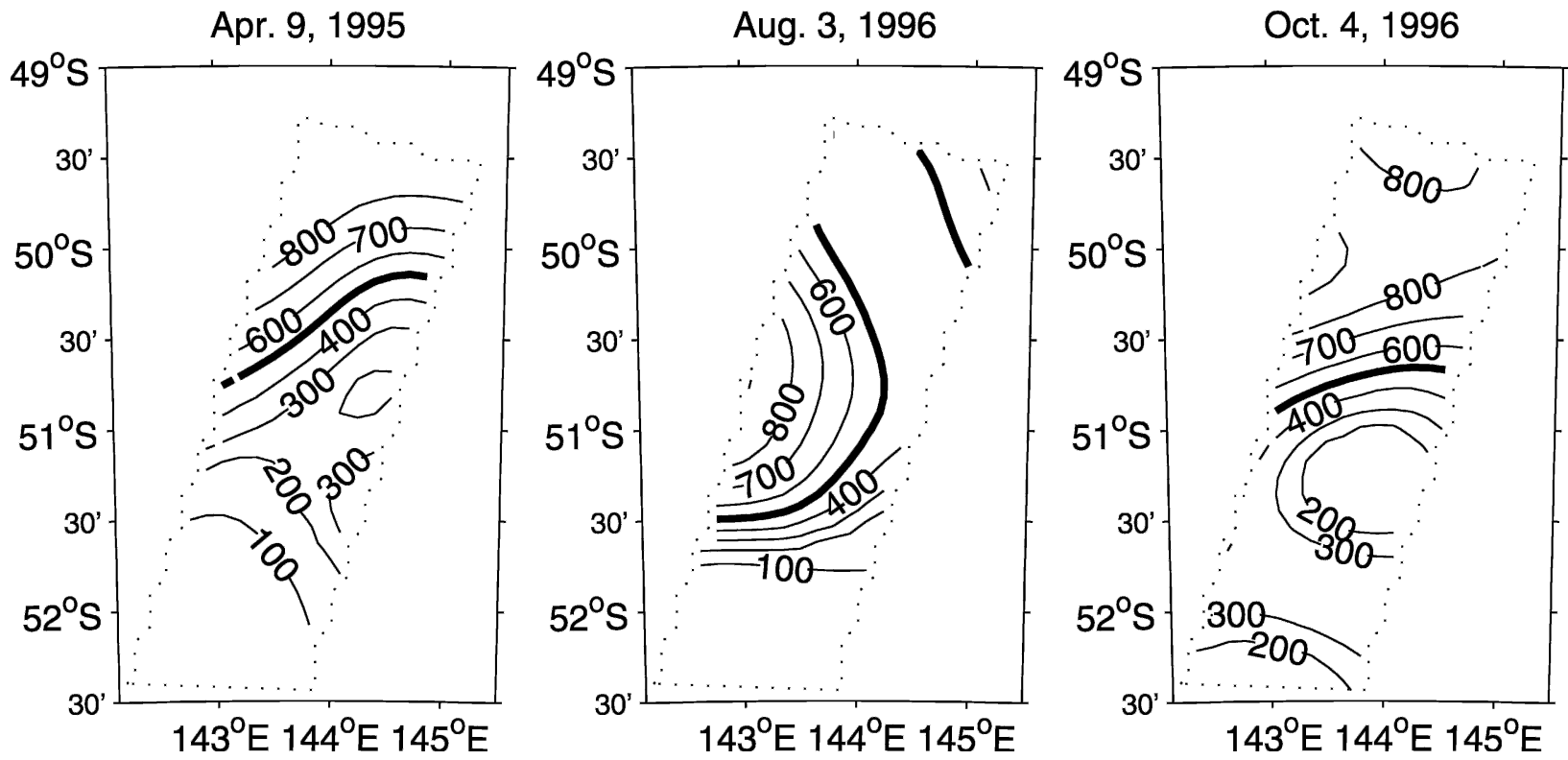

FIG. 4. Maps of the $6^{\circ} \mathrm{C}$ isotherm depth on three days during SAFDE. Contour labels are in $\mathrm{db}$; the bold contour denotes $500 \mathrm{db}$, which is the approximate core of the SAF current (Meinen and Luther 2003). The dotted line indicates edge of the OI mapping domain. 


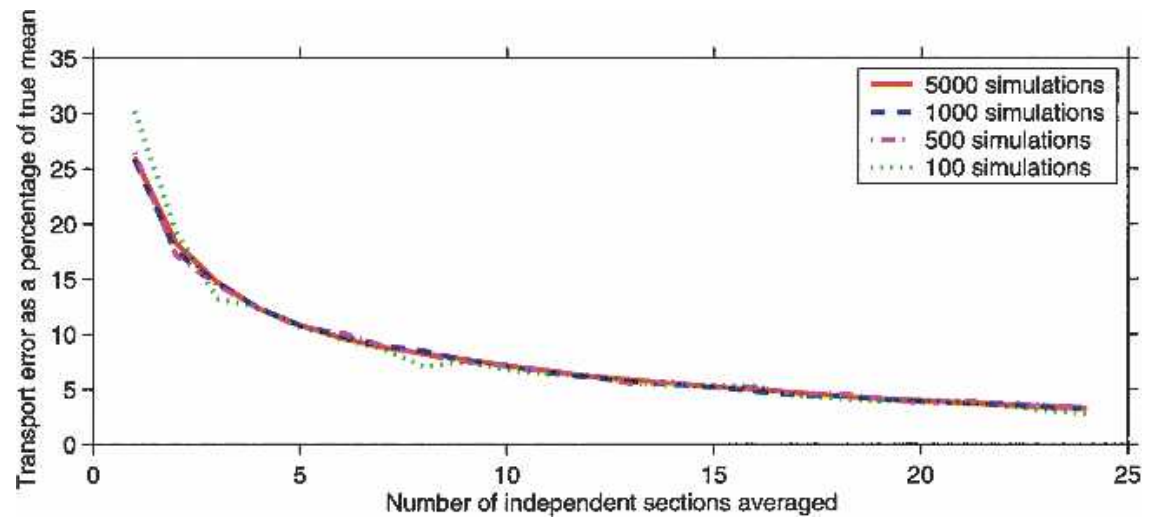

FIG. 5. Transport difference between the average of a series of simulated sections and the true mean transport, reported as a percentage of the true mean transport of $57 \mathrm{~Sv}$. To avoid aliasing the error based on any particular set of sections, a Monte Carlo-type method was applied, using from 100 to 5000 simulations to test the dependence of the results on the number of simulations (number of Monte Carlo simulations indicated in legend). This error represents a one-standard-error level in a normal distribution sense; difference values will exceed this level $33 \%$ of the time, while transport differences will exceed twice this level $5 \%$ of the time, etc. The maximum (minimum) transport for a single daily section during the experiment was $93 \mathrm{~Sv}(12 \mathrm{~Sv})$.

structure can be when a series of snapshot sections is used to try to describe a meandering current such as the SAF. In what follows, first the errors in estimating transport will be discussed, and then the errors in quantifying the mean $T$ and velocity sections will be presented. Errors are quantified for both Eulerian and stream coordinates averaging.

\section{a. Eulerian estimation of the baroclinic transport}

An individual snapshot section across a limited domain in the presence of a meandering current is unlikely to provide a reasonable estimate of the mean baroclinic transport through that domain. This is not a particularly surprising or interesting statement. The SAFDE dataset provides an opportunity, however, to determine just how many sections would be necessary to obtain a reasonable mean; in essence, this is a metric of the observed variability of the SAF at this location. The baroclinic transport relative to $4000 \mathrm{db}$ was integrated across the $350-\mathrm{km}$ range of the IES mapping array (see Fig. 2) for a series of different numbers of simulated "sections"; the difference between the averages of these sections and the true mean was determined for samples of from 1 to 24 sections (Fig. 5).

Monte Carlo-type repeats were made for sets of 100, 500,1000 , and 5000 random subsamples of days; there was little appreciable difference between 500,1000, and 5000 repeated subsets. The differences shown in Fig. 5 represent the rms difference between the 500 (e.g.) estimates of the mean and the true mean. Mathematically, this can be written as $\left[1 / N \Sigma_{i=1}^{N}\left(\Lambda_{i}-\langle\Lambda\rangle\right)^{2}\right]^{0.5}$, where $\Lambda_{i}$ is the $i$ th sample mean and $\langle\Lambda\rangle$ is the true mean. What is clear from Fig. 5 is that the transport "error" between averaged sections and the true mean drops off rapidly as more sections are used up until a point, from a $25 \%$ transport error if only 1 section is used to about $7 \%$ if 10 sections are used. The full record represents about 25-27 degrees of freedom, based on the observed integral time scale of about 12 days, so the maximum number of "independent" sections that can be obtained in any one sample is limited to less than 25 . The error seems to asymptote at about $3 \%$ above 20 sections; the remaining 3\% variance indicates the level of transport variation introduced by time scales other than the dominant frequency represented by the integral time scale.

The transport comparisons (Fig. 5) clearly indicate that in order to obtain a mean baroclinic transport for a 2 -yr period across the $350-\mathrm{km}$ range of the OI mapping domain that is accurate to within 10\% two-thirds of the time would require six temporally independent sections. To get a transport that would be accurate to within $10 \%$ of the truth $95 \%$ of the time would require 15 sections. Keep in mind also that this is a test of how many sections would be required to accurately reproduce a true 2-yr mean; the extrapolation of this result to longer time periods requires additional thought. Longer time periods will involve additional degrees of freedom, and as such 15 random sections will represent a smaller fraction of the total number of dominant degrees of freedom. To the extent that the dominant variability period determined from a 2-yr time series is the same as the actual long-term dominant period, the transport errors should be roughly equal to those shown in Fig. 5. If there is longer period variability that is significant, however, at interannual and longer time scales that would not be evident in a 2-yr record, then the error percentage for determining the time-mean 
transport using only 6 or 15 sections over a longer period than 2 yr would be larger than the percentages shown in Fig. 5.

Another consideration to keep in mind is that some unknown fraction of the variance observed during SAFDE is due to the SAF meandering partially in and out of the experiment array. Therefore, longer hydrographic sections such as the WOCE SR3 repeat lines (Rintoul and Sokolov 2001) would experience lower variations in the total SAF transport. Meinen and Luther (2003) demonstrate, however, that there are significant variations in the baroclinic structure of the SAF within the array domain. Over the 2-yr study the slope of the thermocline at the core of the front was observed to change by a factor of \pm 2 . Furthermore, the baroclinic velocities and transports at the core of the SAF, during the SAFDE time period and within the experiment domain, had a standard deviation equal to or exceeding $50 \%$ of the mean value at all depths. These changes in SAF velocity and transport could have been balanced by changes in the transport along the Polar Front, yielding no change in the net ACC transport. Absent other data it is impossible to state whether there are significant ACC transport variations, which would suggest that snapshot basinwide sections could have transport errors consistent with those indicated in Fig. 5, or whether observed variations at the SAF are compensated elsewhere yielding little change in the net transport across a section between Australia and Antarctica. Regardless, mean transports will be presented shortly from a stream coordinates analysis that determined the transport within horizontal bounds fixed to features of the SAF current. Therefore, these transports will not suffer from the open boundary problem, and yet it will be shown that significant errors in estimating the mean transport along the SAF are still obtained by averaging limited numbers of snapshots.

\section{b. Errors in determining the Eulerian mean $T, u$, and $v$ structure}

The structure of a current determined with a single snapshot section is also not likely to closely approximate the mean structure of that current. Even repeated sections, however, will not necessarily provide a good estimate of the mean structure of a front/current system; Fig. 6 illustrates the true Eulerian mean $u$, $v$, and $T$ sections from SAFDE along the meridional section illustrated in Fig. 2 as well as two sample average sections that each incorporated 10 random "independent" sections.

While the differences in $T$ (Figs. 6c, 6f, and 6i) and in $v$ (Figs. 6b, 6e, and 6h) are perhaps tolerably small in terms of structure and magnitude, the differences in $u$ are very significant. In Fig. $6 g$ the difference in core strength between the northern and southern cores is nearly 2 to 1 , while in truth the mean difference in strength is more like $25 \%-30 \%$. And the 10 -section average shown in Fig. 6d is nothing like the true mean zonal flow; with this average section one would argue that there was a single strong core through the $350-\mathrm{km}$ domain, which is inconsistent with the true 2-yr mean shown in Fig. 6a. So even if 10 sections are sufficient to get the transport accurate to within $7 \%$ or so at the one-standard-error level, that does not mean the structure of the front/current system will look anything like reality when those 10 sections are averaged together.

The sample average sections shown in Figs. 6d-i represent just two random selections of 10 days each; to quantify the errors properly, a Monte Carlo approach is necessary for looking at the structure of the current as well. Because the transport showed little appreciable difference for Monte Carlo simulations of 500, 1000, and 5000 random samplings, 500 samplings will be applied to all of the further calculations of random section averages. Figure 7 illustrates the true mean temperature section as well as the rms errors for 500 random samplings of $1,5,10,15$, and 20 daily sections.

The largest errors track the thermocline as it deepens toward the north along the section, with rms errors as large as $1{ }^{\circ} \mathrm{C}$ above $1000 \mathrm{db}$ for a single section and values of only a few hundredths of a degree Celsius below $1500 \mathrm{db}$ for averages of five sections or more. Note that while the magnitude of the errors has a structure similar to that of the mean section itself, there is no horizontal correlation implied in these error fields. For example, at $-52^{\circ} \mathrm{N}$ at $500 \mathrm{db}$ in the five-section averages (Fig. 7c) there is an rms error of about $0.3^{\circ} \mathrm{C}$, and at $-51.5^{\circ} \mathrm{N}$ there is a similar magnitude of error. The errors, however, may be of completely different sign at the two locations, so the temperature could be too high at $-52^{\circ} \mathrm{N}$ and too low at $-51.5^{\circ} \mathrm{N}$, or vice versa. The zonal velocity sections shown in Figs. $6 \mathrm{~d}$ and $6 \mathrm{~g}$ clearly illustrated that in addition to magnitude errors the temporal scatter can result in significant horizontal and vertical structure differences as well.

The "true" mean meridional velocity and the rms errors for using 1, 5, 10, 15, and 20 sections to estimate the mean are shown in Fig. 8. For a single section the rms differences from the true mean exceed the mean values over essentially the entire domain (and keep in mind this is a only a one-standard-error bar, so the difference will exceed that shown in the figure about one-third of the time). Even averaging 20 sections together yields errors in the mean velocity exceeding 4 $\mathrm{cm} \mathrm{s}^{-1}$, which is $20 \%-25 \%$ of the largest time-mean meridional velocity signals.

The "true" mean zonal velocity and the rms errors for using 1, 5, 10, 15, and 20 sections to estimate the mean are shown in Fig. 9. Like the meridional velocity, the rms difference between the velocity of a single section and the true mean is equal to or larger than the mean values themselves. This error decreases consistently with the use of more sections for averaging; when 20 sections are averaged together the errors decrease below $4 \mathrm{~cm} \mathrm{~s}^{-1}$, or about $15 \%-25 \%$ of the time-mean value. Again, keep in mind that no horizontal or verti- 
a: True zonal velocity mean

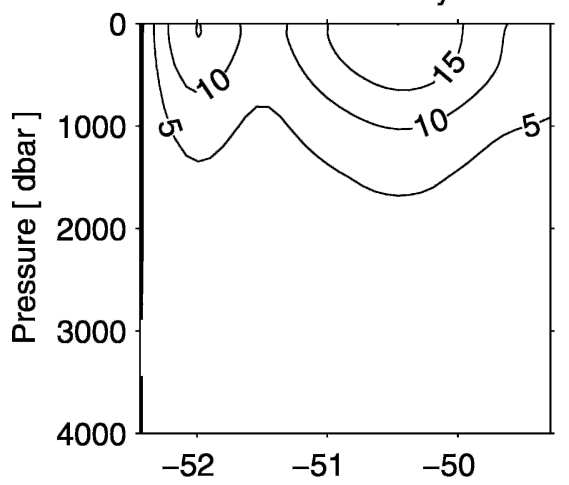

d: Sample zonal velocity mean

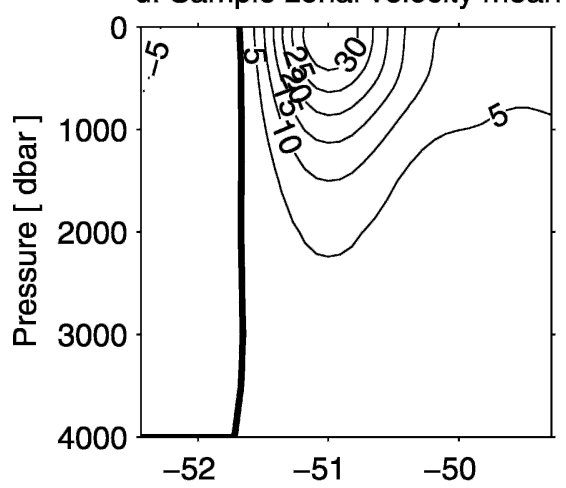

g: Sample zonal velocity mean

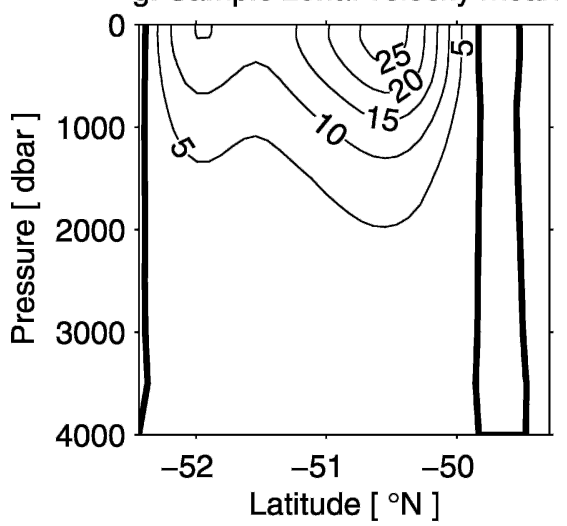

b: True meridional velocity mean

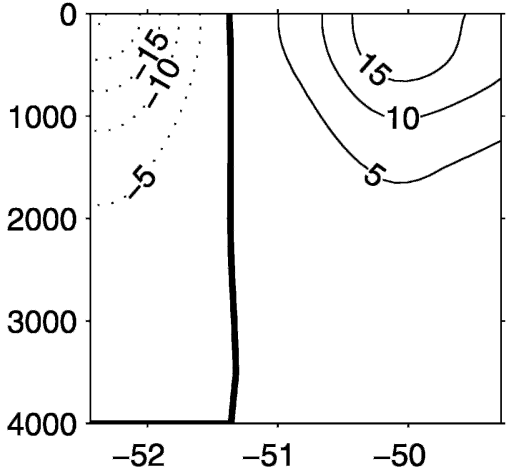

e: Sample meridional velocity mean

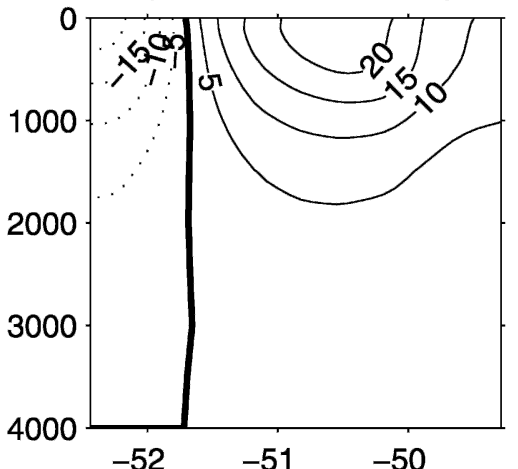

$\mathrm{h}$ : Sample meridional velocity mean

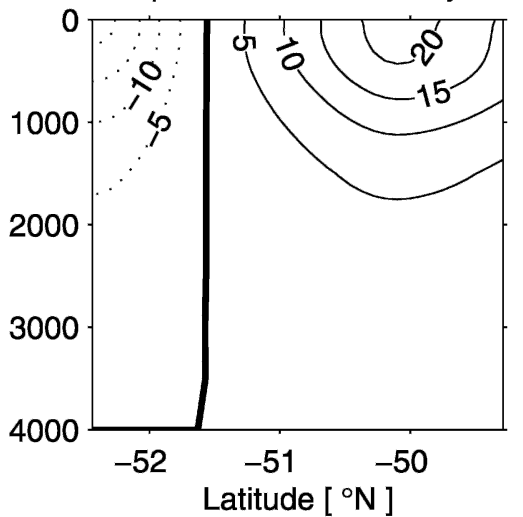

c: True temperature mean

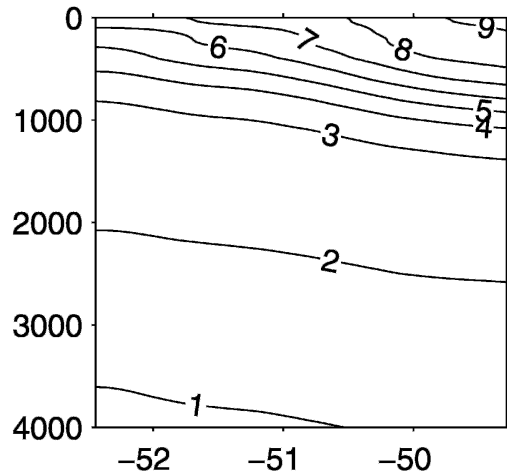

f: Sample temperature mean

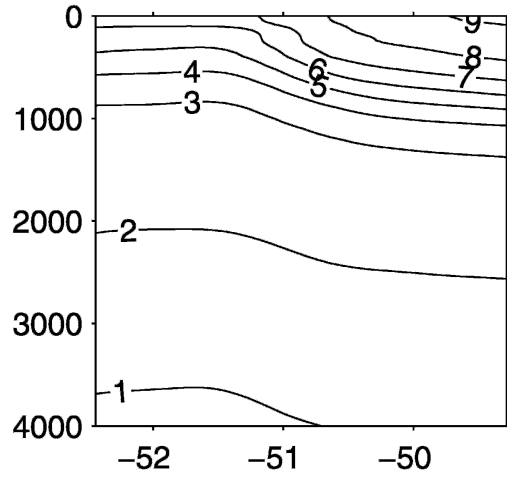

i: Sample temperature mean

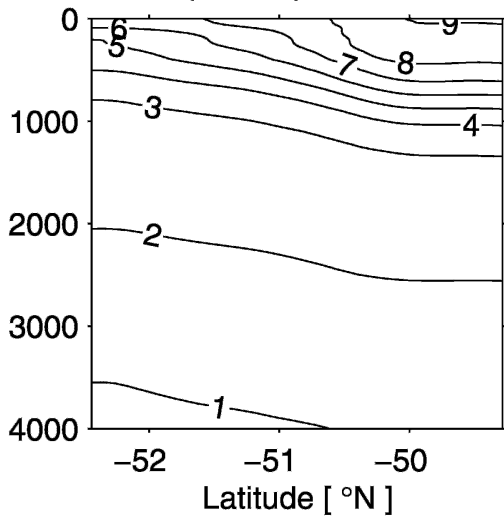

FIG. 6. Comparison of the true mean sections of (a) $u$, (b) $v$, and (c) $T$ to two random sample averages of 10 sections each [(d)-(f) correspond to the first average of 10 random sections, while (g)-(i) correspond to the second average of 10 sections]. Units are in $\mathrm{cm} \mathrm{s}$ for the velocity sections and ${ }^{\circ} \mathrm{C}$ for the temperature sections. Bold contour in velocity panels indicates zero velocity, while dashed contours indicate negative (westward or southward) flow.

cal correlation is implied in these error figures; as illustrated in Fig. 6d, the errors in velocity can produce completely different structures, as well as change magnitudes, as illustrated in Fig. 6g.

\section{c. Stream coordinates estimation of the baroclinic transport}

The majority of oceanographers will probably view the above results simply as a problem of a stream co- ordinates versus Eulerian coordinates averaging and/or as a problem with having open boundaries at the edge of the integration. While this clearly contributes to the variability in transport and structure observed by the SAFDE array, the true temporal variations of the SAF current itself are not negligible, and therefore discrete sampling of this varying field will still yield errors when determining the mean transport or structure. Consider first the transport. When a series of repeat hydro- 
a: True temperature mean

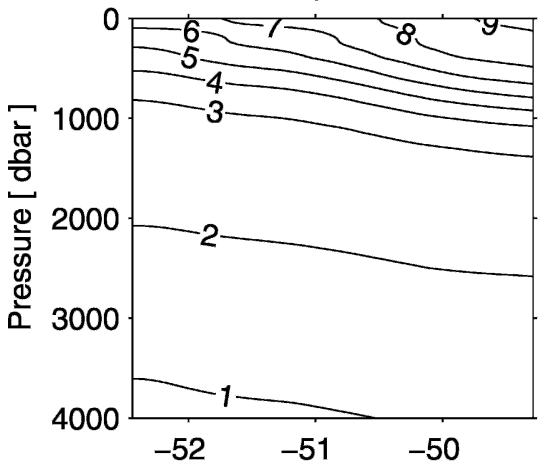

d: RMS error for 10 section average

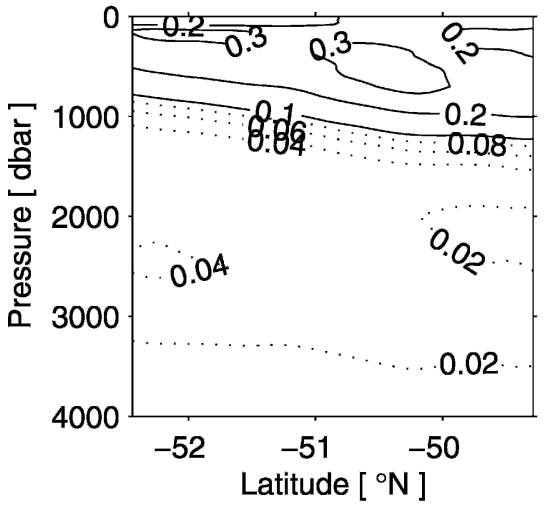

b: RMS error for single section

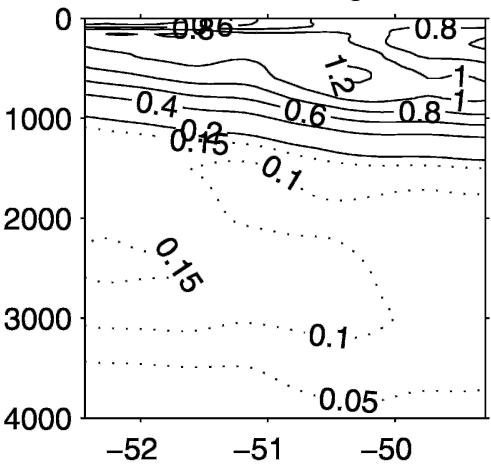

e: RMS error for 15 section average

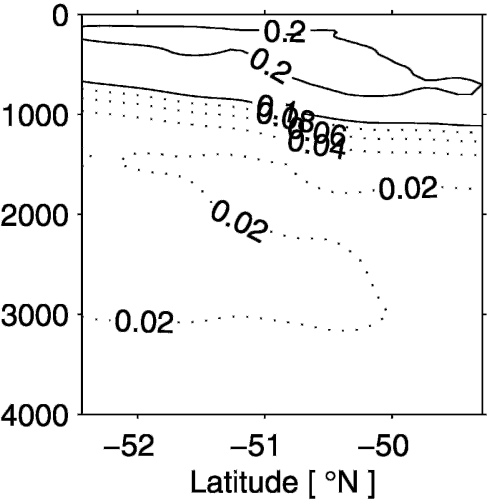

c: RMS error for 5 section average

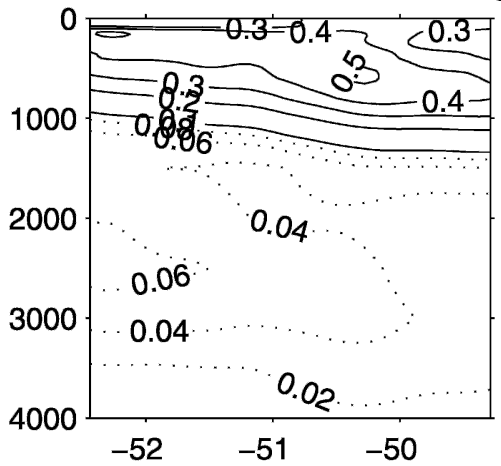

f: RMS error for 20 section average

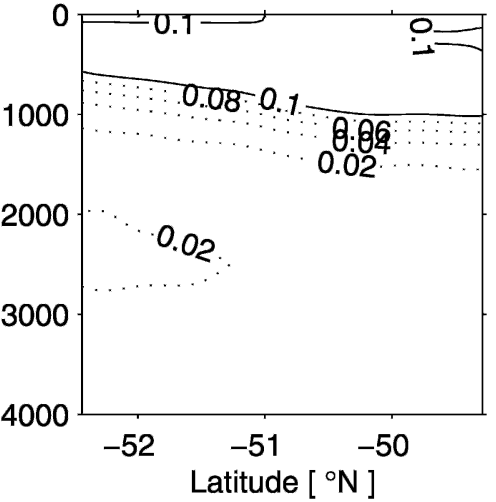

FIG. 7. The (a) true temperature mean and the rms errors determined from 500 random subsamplings of (b) a single section, (c) an average of 5 sections, (d) an average of 10 sections, (e) 15 sections, and (f) 20 sections. Units are in ${ }^{\circ} \mathrm{C}$; note that each panel has a different contour interval and that dotted contours indicate a smaller contour interval than the solid contours.

graphic sections is occupied (e.g., Rintoul and Sokolov, 2001), they generally span across multiple currents, such as the SAF current and the PF current, which make up the ACC. To assign a portion of the observed transport to each current, some definition of the boundaries of the current must be developed; commonly this is a hydrographic definition such as a certain isopycnal crossing a certain pressure surface $\sigma_{p}$. If there is significant vertical coherence in density, ${ }^{6}$ however, this definition essentially predetermines the baroclinic transport, as each $\sigma_{p}$ value will be associated with a nearconstant profile of dynamic height. When the transport is then integrated between these bounds, the same value of transport will always be obtained (this is true regardless of whether one is using hydrography from a CTD section or a GEM-type technique).

Alternate definitions for current boundaries are generally dependent upon the velocity or transport structure. To simulate the transport integration that might be done with hydrographic sections, stream coordinates sections were extracted from the 4D array of SAFDE

\footnotetext{
${ }^{6}$ The success of the GEM method in this region demonstrates that a strong vertical coherence exists.
}

data, and the transports from those snapshot sections were integrated between the locations where the alongstream surface velocity dropped below $10 \mathrm{~cm} \mathrm{~s}^{-1}$ on either side of the core. This criterion was chosen as a balance between including as much of the transport as possible while keeping as many daily sections as possible. The results using $5 \mathrm{~cm} \mathrm{~s}^{-1}$ as the boundary cutoffs were similar, albeit much noisier because of the smaller sample size. To illustrate the boundaries chosen, the stream coordinates mean surface velocity cross section is shown in Fig. 10, along with the $10 \mathrm{~cm} \mathrm{~s}^{-1}$ cutoffs.

For each random subset of days, the transport was integrated between the two bounds and then the transport estimates were averaged to provide a single sample transport mean for that set of random daily snapshots. The resulting differences between the ensemble rms differences and the true transport are shown in the lower panel of Fig. 10. Figure 10 is essentially the stream coordinates equivalent of Fig. 5, although the gap across which the transport is integrated is much smaller here. The fact that the true mean stream coordinates transport across this gap $(53 \mathrm{~Sv})$ and the true mean Eulerian transport across the $350-\mathrm{km}$ span of the SAFDE array (57 Sv) are so close is probably fortu- 


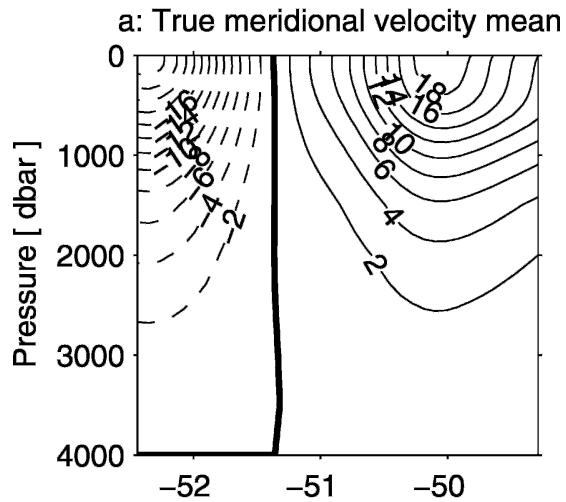

b: RMS error for single section

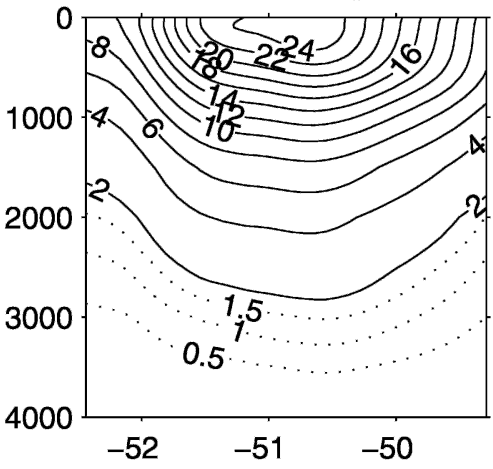

e: RMS error for 15 section average
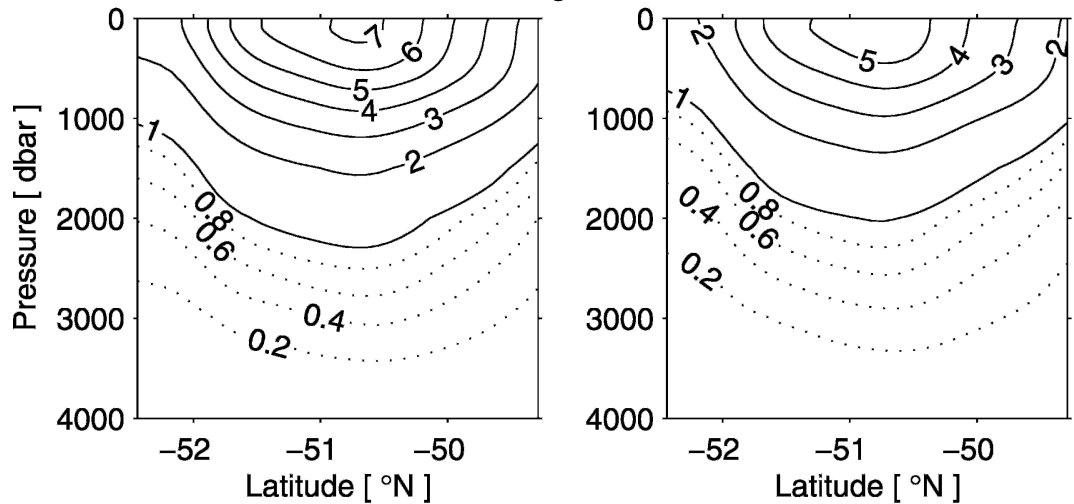

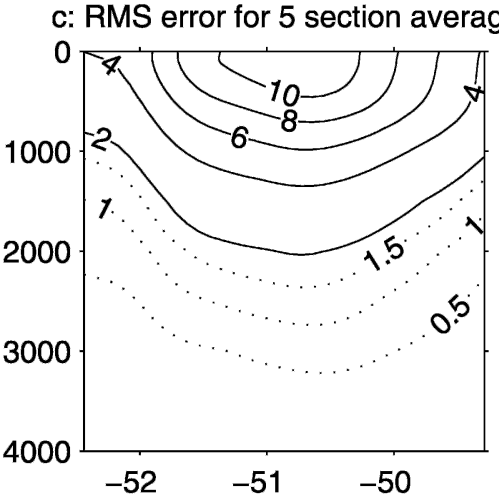

f: RMS error for 20 section average

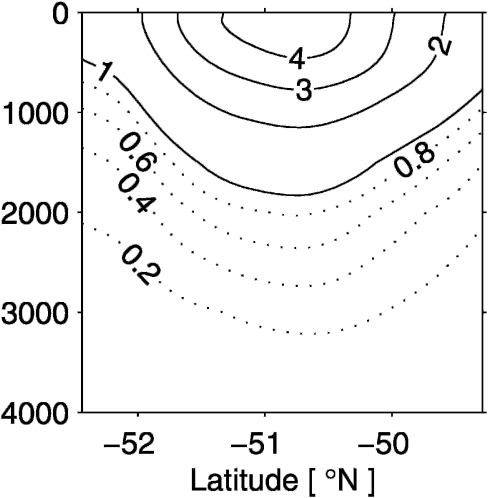

FIG. 8. The (a) true meridional velocity mean and the rms errors determined from 500 random subsamplings of (b) a single section, (c) an average of 5 sections, (d) an average of 10 sections, (e) 15 sections, and (f) 20 sections. Units are in $\mathrm{cm} \mathrm{s}^{-1}$; note that each panel has a different contour interval and that dotted contours indicate a smaller contour interval than the solid contours. In (a) dashed contours indicate negative, southward flow, while bold contour indicates zero flow, and thin solid contours indicate positive, northward flow.

itous. As in Fig. 5, the transport error illustrated in Fig. 10 indicates a precipitous decrease in the error in transport with the addition of additional sections. With a single section across the SAF, properly rotated into stream coordinates and integrated within the bounds illustrated in Fig. 10, the error in baroclinic transport is about $30 \%$. With more than 6 sections averaged together the error drops just below $10 \%$, and with more than 10 sections during the 2-yr period the error appears to be approaching an asymptote at roughly $7 \%$. So while the variability involved in the meanders of the SAF and the variations resulting from the open boundaries without question represented a large fraction of the variance that results in the Eulerian errors shown in Fig. 5, the variations of the SAF itself are large enough that a limited number of snapshots across the SAF will still result in mean baroclinic transport that can be significantly in error relative to the true mean. Meinen and Luther (2003) found $\pm 50 \%$ variations in the peak speed at the core of the SAF during SAFDE; the results shown here indicate that even when integrated within hydrographically reasonable bounds fixed to the flanks of the current there is still significant variability in the current transport along the SAF. With a reasonable number of sections, however, it is possible to reduce the error in the baroclinic transport estimate.

\section{d. Errors in determining the stream coordinates mean $T$, $u$, and $v$ structure}

The velocity sections used to determine the transport were also used to estimate the stream coordinates mean velocity. Cross-stream velocities were calculated; however, as their magnitudes were less than $10 \%$ of the along stream velocity, they are not shown here and we will focus on the along-stream velocity. The outer-edge boundary criteria used for the stream coordinates transport integration are not needed here, as the velocities are not being horizontally integrated, which means that each daily section does not have to reach both of those limits to be usable. Instead, a more general requirement that the stream coordinates section extend at least 60 $\mathrm{km}$ to either side of the core was applied; this allows us to use 280 of the 701 days for the calculation of the mean velocity structure. With additional days come additional independent samples, which allows for the sampling of up to 20 independent samples per Monte 
a: True zonal velocity mean

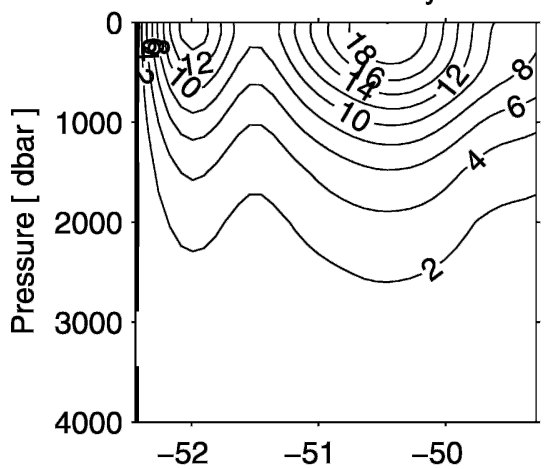

d: RMS error for 10 section average

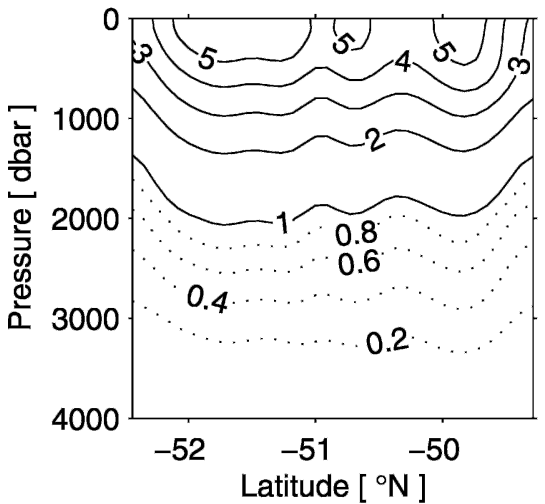

b: RMS error for single section

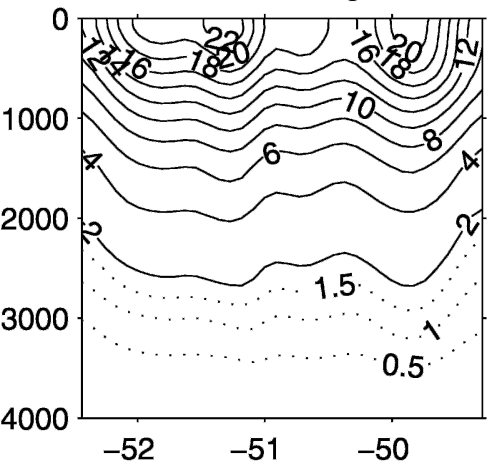

e: RMS error for 15 section average

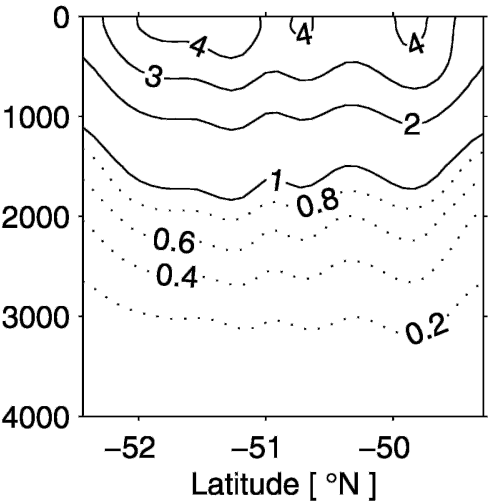

c: RMS error for 5 section average

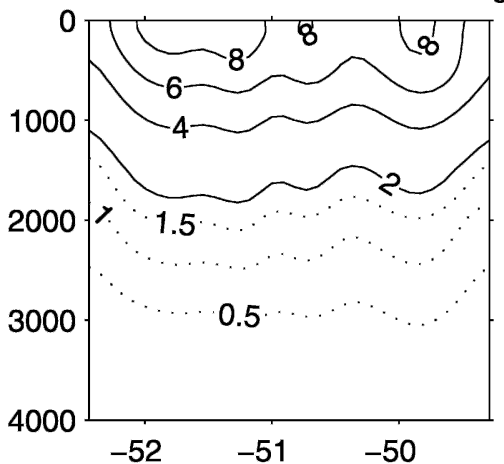

f: RMS error for 20 section average

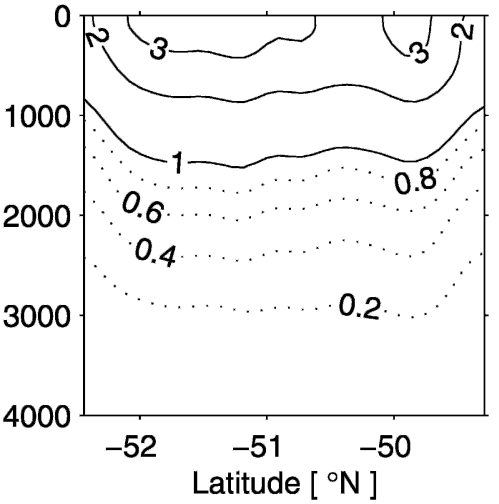

FIG. 9. The (a) true zonal velocity mean and the rms errors determined from 500 random subsamplings of (b) a single section, (c) an average of 5 sections, (d) an average of 10 sections, (e) 15 sections, and (f) 20 sections. Units are in $\mathrm{cm} \mathrm{s}^{-1}$; note that each panel has a different contour interval and that dotted contours indicate a smaller contour interval than the solid contours.

Carlo simulation. The resulting mean along-stream velocity section, and the rms errors determined for samples of $1,5,10,15$, and 20 sections, are presented in Fig. 11.

As expected, the velocity core is much stronger and more organized when calculated in stream coordinates (Fig. 11a), with peak speeds just over $40 \mathrm{~cm} \mathrm{~s}^{-1}$. The rms differences between the 500 sample single velocity sections and the true mean section are greater than $50 \%$ of the mean value (Fig. 11b), and the rms errors in calculating the true mean using increasing numbers of sections are smaller. With 20 sections averaged together during a 2-yr period (Fig. 11f) the rms differences represent about $10 \%$ of the true time-mean along-stream velocity. There are oceanographic repeat sections being taken with a frequency of at least 20 sections in 2 yr (e.g., the Oleander experiment; Rossby and Zhang 2001); however, in most cases such frequency is simply not practical. A far more realistic goal would be to have about five sections during a 2-yr period, which would yield approximately $25 \%$ errors relative to the true mean (Fig. 11c). As was noted previously, if the variability during the 2-yr period of SAFDE is representative of the long-term variability (i.e., there is little interannual or longer variability), then there is no requirement that all of these repeat sections be taken during a 2-yr window and a stream coordinate mean section could be built using hydrography taken over many years. If, however, there is significant variability at longer time scales than can be observed by SAFDE, then the errors in a mean developed using hydrography spread over a longer time period would be even larger than those shown in Fig. 11.

\section{e. Barotropic variability}

This study of velocity variability has focused on the baroclinic flow relative to $4000 \mathrm{db}$ for the simple reason that there is insufficient data to calculate the barotropic transport in the same manner at the same horizontal resolution over a long section such as that shown in Fig. 2. The barotropic transport of the SAF, defined as the bottom velocity multiplied by the water column depth, after Fofonoff (1962), is not always negligible, however, so a brief comment is in order. Using the barotropic information available at the HEFR sites within the IES array (Fig. 1), the barotropic flow has been shown to be weak in the mean during the SAFDE period, but at times the deep currents exceeded $10 \mathrm{~cm} \mathrm{~s}^{-1}$ for periods of weeks (Meinen et al. 2002, 2003). Furthermore, at the HEFR sites it is clear that the deep currents are 

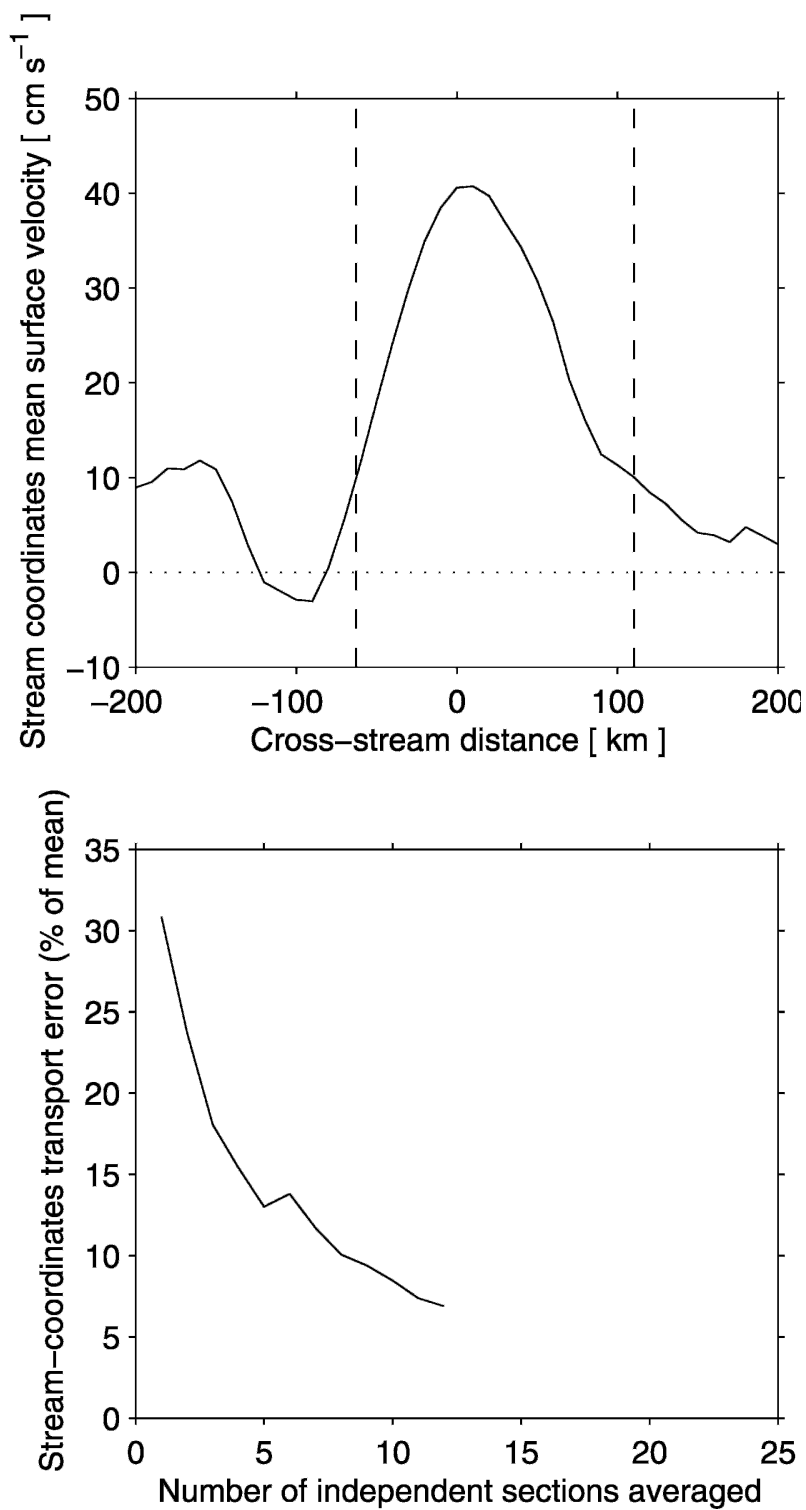

FIG. 10. (top) Stream coordinates mean surface velocity cross section derived as described in text. Vertical dashed lines indicate the boundaries used in integrating transport. (bottom) Difference between the sample mean transport from a series of stream coordinates sections and the true mean transport, reported as a percentage of $53 \mathrm{~Sv}$. Transport for each daily section was integrated between the points where the surface velocity dropped below $10 \mathrm{~cm} \mathrm{~s}^{-1}$ on either side of the core. As in the Eulerian tests, a Monte Carlo-type approach was used utilizing 500 simulations. Because fewer of the days had stream coordinates sections that spanned the full gap between $10 \mathrm{~cm} \mathrm{~s}^{-1}$ isotachs, the largest number of random samples that could be extracted from the dataset was 12 .

uncorrelated with the thermocline layer flows. This suggests that absolute transport and velocity structure accuracies from averages of hydrographic sections, where the geostrophic velocities have been referenced using shipboard or lowered acoustic Doppler current profiler data or through other absolute velocity measurements, may be even worse than is suggested by Figs. 5, 8, 9, 10, and 11.

\section{Conclusions}

At first glance this paper might be viewed simply as an attack on the use of hydrography to study oceanic currents; however, that is neither the purpose of this paper nor is it in truth the right overall conclusion to draw from these results. Figure 5 clearly indicates that with more than five sections during a 2-yr period the baroclinic transport across a $350-\mathrm{km}$ span is known to within an accuracy of roughly $10 \%$. The velocity and temperature structure, however, are still poorly known with even 10 sections obtained during a 2-yr period and averaged in an Eulerian manner. Of course, the latter result is dependent on the use of a fixed section path when crossing a meandering current; when the velocity sections are rotated and averaged in a stream coordinates manner (e.g., Rossby and Zhang 2001; Meinen and Luther 2003) individual section data can be adjusted to account for the movement of the front prior to averaging in order to produce a better estimate of the velocity structure associated with a front. The mean section of along-stream velocity calculated in stream coordinates from a combination of 10 sections is much more accurate than the Eulerian mean of 10 sections (15\% errors rather than $28 \%$ errors; see Figs. 9 and 11$)$, although the $15 \%$ errors of the stream coordinates section average are still somewhat unpalatable. Hydrographic observations in regions with high temporal variability such as the SAFDE region are clearly better suited to providing time-mean estimates of integral quantities, such as transport over long spans, rather than details of the velocity and temperature structure.

In addition to motivating the use of more detailed analysis techniques such as stream coordinates for the use of repeat hydrographic sections near strongly meandering fronts, this work is also providing estimates of the variability that should be applied in inverse models that incorporate small numbers of sections to estimate the mean circulation patterns (e.g., Gille 1999; Yaremchuk et al. 2001; Lumpkin and Speer 2003). The standard linear inverse modeling techniques require that an estimate of the baroclinic temporal variance be included in order to allow the model to provide a formal error bar for the resulting model output, such as overturning and mixing estimates (Wunsch 1996). A number of studies have recently sought to better quantify the errors associated with inverse models either by shifting to a nonlinear inverse technique that allows for baroclinic adjustment in the inverse calculation (e.g., Paillet and Mercier 1997) or by utilizing numerical model outputs for estimating the true variability (e.g., Ganachaud 1999). While most inverse models are done using basin-spanning sections, not short sections like 
a: Along-stream velocity mean

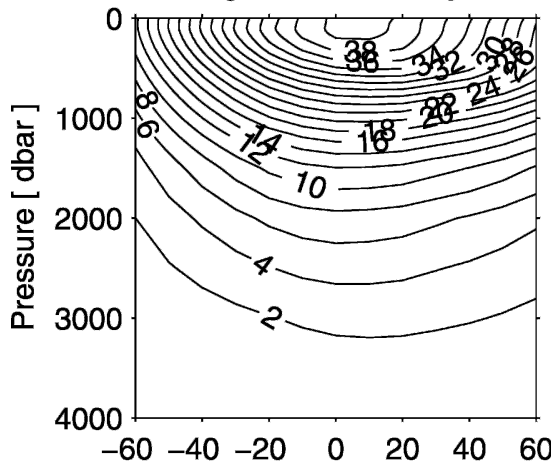

d: RMS error for 10 section average

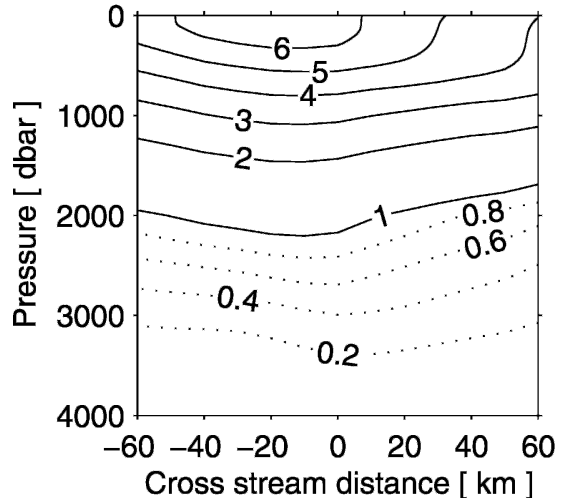

b: RMS error for single section
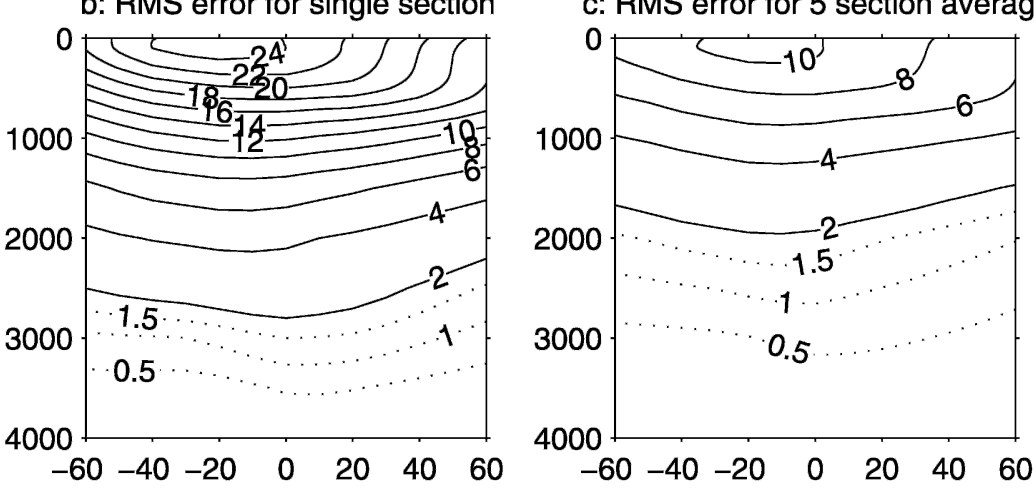

e: RMS error for 15 section average

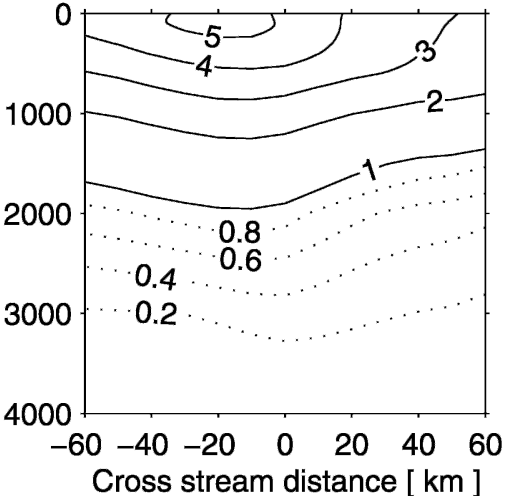

c: RMS error for 5 section average

f: RMS error for 20 section average

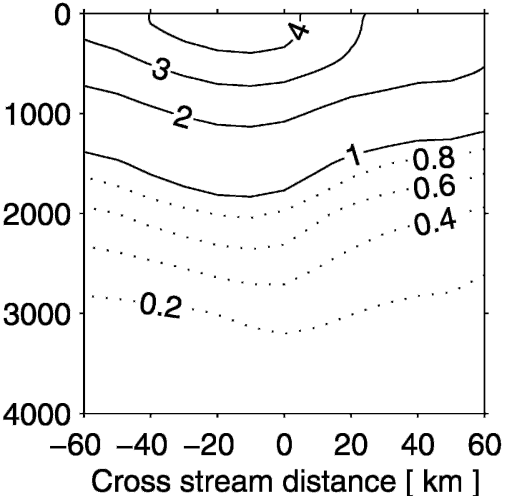

FIG. 11. Same as in Fig. 9 except for stream coordinates mean rather than Eulerian mean.

the SAFDE mooring domain, these inverse models often apply separate constraints on the strong ocean currents (e.g., the Gulf Stream) within their domain versus the constraints applied in the basin interior. Therefore, the baroclinic estimates from the stream coordinates results herein will prove useful for such models. By utilizing an array of moored instruments, this study has demonstrated using in situ observations that any single north-south section across the SAF should be accompanied by a $25 \%$ baroclinic transport error bar for a span of $350 \mathrm{~km}$ (Fig. 5) ${ }^{7}$ and zonal baroclinic velocity variance estimates of about $100 \%$ (Fig. 9). By comparing the observed variance at other locations around the globe to the observed variance at the location of the SAFDE it may be possible to expand these results beyond this particular portion of the Southern Ocean to provide estimates of the true baroclinic variability in other regions.

Acknowledgments. The author would like to thank Randy Watts, Karen Tracey, and Che Sun for the OImapped IES observations, Jim Richman for the CMM

\footnotetext{
${ }^{7}$ As noted earlier, however, this transport error bar may be smaller for a section fully crossing a basin.
}

temperature and pressure records used in making the one pseudo-IES record, Steve Rintoul for some of the hydrography used in this study, and Sarah Gille for her SAF position used in Fig. 1. Numerous helpful discussions with Molly Baringer, Doug Luther, Karen Tracey, and Randy Watts aided in this work, and their help is greatly appreciated. Rick Lumpkin, Bob Molinari, and two anonymous reviewers provided several very productive comments for improving this manuscript. Some of the data preparation for this study was completed under funding from NSF Grant OCE-9911974. The author was funded for this work under the auspices of the Cooperative Institute for Marine and Atmospheric Studies (CIMAS), a joint institute of the University of Miami and the National Oceanic and Atmospheric Administration (NOAA), Cooperative Agreement NA67RJ0149.

\section{REFERENCES}

Bretherton, F. P., R. E. Davis, and C. B. Fandry, 1976: A technique for objective analysis and design of oceanographic experiments applied to MODE-73. Deep Sea Res., 23A, 559582.

Chaplin, G. F., and D. R. Watts, 1984: Inverted echo sounder development. IEEE Oceans '84 Conference Record, Vol. 1, IEEE, 249-253.

Chave, A. D., D. S. Luther, and C. S. Meinen, 2004: Correction of 
motional electric field measurements for galvanic distortion. J. Atmos. Oceanic Technol., 21, 317-330.

Emery, W. J., and R. E. Thomson, 1997: Data Analysis Methods in Physical Oceanography. Pergamon Press, $634 \mathrm{pp}$.

Fofonoff, N. P., 1962: Dynamics of ocean currents. The Sea: Ideas and Observations on Progress in the Study of the Seas, M. N. Hill, Ed., Physical Oceanography, Vol. 1, Wiley-Interscience, 323-395.

Ganachaud, A. S., 1999: Large scale oceanic circulation and fluxes of freshwater, heat, nutrients and oxygen. Ph.D. thesis, Massachusetts Institute of Technology-Woods Hole Oceanography Institution Joint Program, 249 pp.

Gille, S. T., 1994: Mean sea surface height of the Antarctic Circumpolar Current from Geosat data: Method and application. J. Geophys. Res., 99, 18 255-18 273.

_- 1999: Mass, heat, and salt transport in the southeastern Pacific: A Circumpolar Current inverse model. J. Geophys. Res., 104, 5191-5209.

Halkin, D., and H. T. Rossby, 1985: The structure and transport of the Gulf Stream at $73^{\circ}$ W. J. Phys. Oceanogr., 15, 1439-1452.

Johns, W. E., T. J. Shay, J. M. Bane, and D. R. Watts, 1995: Gulf Stream structure, transport, and recirculation near $68^{\circ} \mathrm{W}$. $J$. Geophys. Res., 100, 817-838.

Koltermann, K. P., A. V. Sokov, V. P. Tereschenkov, S. A. Dobroliubov, K. Lorbacher, and A. Sy, 1999: Decadal changes in the thermohaline circulation of the North Atlantic. Deep Sea Res., 46B, 109-138.

Lumpkin, R., and K. Speer, 2003: Large-scale vertical and horizontal circulation in the North Atlantic Ocean. J. Phys. Oceanogr., 33, 1902-1920.

Luther, D. S., A. D. Chave, J. A. Church, J. H. Filloux, J. G. Richman, S. R. Rintoul, and D. R. Watts, 1997: The SubAntarctic Flux and Dynamics Experiment (SAFDE). WOCE Notes, 9, 8-12.

Meinen, C. S., and D. R. Watts, 2000: Vertical structure and transport on a transect across the North Atlantic Current near $42^{\circ} \mathrm{N}$ : Time series and mean. J. Geophys. Res., 105, 21869 21891.

, and D. S. Luther, 2003: Comparison of methods of estimating mean synoptic current structure in "stream coordinates" reference frames with an example from the Antarctic Circumpolar Current. Deep Sea Res., 50A, 201-220.

, - D. R. Watts, K. L. Tracey, A. D. Chave, and J. Rich- man, 2002: Combining inverted echo sounder and horizontal electric field recorder measurements to obtain absolute velocity profiles. J. Atmos. Oceanic Technol., 19, 1653-1664.

,,--- , A. D. Chave, and K. L. Tracey, 2003: Mean stream coordinates structure of the Subantarctic Front: Temperature, salinity, and absolute velocity. J. Geophys. Res., 108, 3263, doi:10.1029/2002JC001545.

Paillet, J., and H. Mercier, 1997: An inverse model of the eastern North Atlantic general circulation and thermocline ventilation. Deep Sea Res., 44A, 1293-1328.

Phillips, H. E., and S. R. Rintoul, 2000: Eddy variability and energetics from direct current measurements in the Antarctic Circumpolar Current south of Australia. J. Phys. Oceanogr., 30, 3050-3076.

Rintoul, S. R., and S. Sokolov, 2001: Baroclinic transport variability of the Antarctic Circumpolar Current south of Australia (WOCE repeat section SR3). J. Geophys. Res., 106, 28152832.

Rossby, T., and H.-M. Zhang, 2001: The near-surface velocity and potential vorticity structure of the Gulf Stream. J. Mar. Res., 59, 949-975.

Shay, T. J., J. M. Bane, D. R. Watts, and K. L. Tracey, 1995: Gulf Stream flow field and events near $68^{\circ} \mathrm{W}$. J. Geophys. Res., 100, 22 565-22 589.

Smith, W. H. F., and D. T. Sandwell, 1997: Global sea floor topography from satellite altimetry and ship depth soundings. Science, 277, 1956-1962.

Sun, C., and D. R. Watts, 2002: A pulsation mode in the Antarctic Circumpolar Current south of Australia. J. Phys. Oceanogr., 32, 1479-1495.

Watts, D. R., and H. T. Rossby, 1977: Measuring dynamic heights with inverted echo sounders: Results from MODE. J. Phys. Oceanogr., 7, 345-358.

— C. Sun, and S. Rintoul, 2001: A two-dimensional gravest empirical mode determined from hydrographic observations in the Subantarctic Front. J. Phys. Oceanogr., 31, 2186-2209.

Wunsch, C., 1996: The Ocean Circulation Inverse Problem. Cambridge University Press, $442 \mathrm{pp}$.

Yaremchuk, M., N. L. Bindoff, J. Schröter, D. Nechaev, and S. R. Rintoul, 2001: On the zonal and meridional circulation and ocean transports between Tasmania and Antarctica. J. Geophys. Res., 106, 2795-2814. 